\title{
Orbitofrontal sulcal and gyrus pattern in human: an anatomical study
}

\author{
Padrões de sulcos e giros orbitofrontais em humanos: um estudo anatômico \\ Thiago Pereira Rodrigues', Mariana Athaniel Silva Rodrigues², Daniel de Araújo Paz', Marcos Devanir Silva \\ da Costaํ, Ricardo Silva Centeno', Feres Eduardo Chaddad-Neto', Sergio Cavalheiro'
}

\begin{abstract}
The anatomical characterization of the orbitofrontal cortex in human is limited in literature instead of many functional and clinical studies involving it. Objective: Anatomically define the orbitofrontal region aiming to possible neurosurgical treatments and unify the scientific nomenclature as well. Method: We analyze eighty four human hemispheres using a surgical microscope. Then we chose four hemispheres and dissect them according to Klinger' technique. Results: We found five main sulcus: olfatory sulcus, orbital medial sulcus, orbital lateral sulcus, orbital transverse sulcus and orbital intermediate sulcus. These sulcus, excluding the intermediate sulcus, delimit five gyrus: rectus gurys, orbital medial gyrus, orbital anterior gyrus, orbital lateral gyrus and orbital posterior gyrus. The main sulcal configuration can be divided on four more frequently patterns. Conclusion: Orbitofrontal cortex is associated with many psychiatric disorders. Better anatomical and functional characterization of the orbitofrontal cortex and its connections will improve our knowledge about these diseases.
\end{abstract}

Keywords: neuroanatomy, frontal lobe, gyrus pattern.

\section{RESUMO}

A caracterização do córtex orbitofrontal em humanos é limitada na literatura, a despeito de estudos funcionais e clínicos envolvendo-o. Objetivo: Definir anatomicamente o córtex orbitofrontal visualizando possíveis tratamentos neurocirúrgicos e unificar a nomenclatura científica. Método: Analisamos oitenta e quatro hemisférios cerebrais humanos usando um microscópio neurocirúrgico. Escolhemos quatro hemisférios e os dissecamos de acordo com a técnica de Klinger para expor a substância branca subcortical. Resultados: Encontramos cinco principais sulcos: sulco olfatório, sulco orbital medial, sulco orbital lateral, sulco orbital transverso e sulco orbital intermediário. Estes sulcos, excluindo o sulco orbital intermediário, delimitaram cinco giros: giro reto, giro orbital medial, giro orbital anterior, giro orbital lateral e giro orbital posterior. A conformação de sulcos e giros orbitais pôde ser dividida em quatro padrões mais frequentes. Conclusão: 0 córtex orbitofrontal é associado com várias desordens psiquiátricas. Uma melhora caracterização anatômica, funcional e de suas conexões melhorará nosso conhecimento destas desordens.

Palavras-chave: neuroanatomia, lobo frontal, giros orbitais.

The cerebral cortex folding in humans allow that an extensive area of cerebral cortex fit into the limited space of the skull. The factors that guide this folding are complex and its final result leads to sulci and gyrus patterns in adult brain. These patterns, depending on the region of cerebral cortex analyzed, can have or not a high degree of variability ${ }^{1}$.

There are some evidence that factors guiding the cerebral cortex folding starts in the beginning of cerebral morphogenesis. First, in a coronal brain slice, we can see that sulcus in the inferior and lateral surface of the brain are oriented toward the ventricular cavity and sulcus in the medial surface are oriented parallel to corpus callosum fibers. (In cases of total corpus callosum agenesis, the sulcus in the medial surface seems to be ventricular-guided too). Second, neurons sends axons across the corpus callosum even before the neuron migration process end ${ }^{2}$, and this neuronal projection affect the final brain morphology ${ }^{3}$. Based on these observations, we can suppose that the final brain morphology depends on neuronal migration, axonal connection and probably others factors.

The frontal lobe has four surfaces: a lateral, a medial, a basal and a sylvian surface ${ }^{4}$. The basal surface is in contact with the orbital roof, compounded of the frontal, ethmoid and sphenoid bones being, for this reason, called orbitofrontal surface.

In the last ten years, many studies have showed the relationship between altered orbitofrontal cortical pattern and

1 Universidade Federal de São Paulo, Escola Paulista de Medicina, Disciplina de Neurocirurgia, Sao Paulo SP, Brazil;

${ }^{2}$ Hospital Albert Einstein, Disciplina de Radiologia, Sao Paulo SP, Brazil.

Correspondence: Thiago Pereira Rodrigues; Rua das Camélias, 29 / ap. 31; 04048-060 São Paulo SP, Brasil; E-mail: thiagopereirarodrigues@yahoo.com.br Conflict of interest: There is no conflict of interest to declare.

Received 19 November 2014; Received in final form 22 December 2014; Accepted 14 January 2015. 
psychiatric disorders ${ }^{5}$. We know that a high degree of variability exists in the folding of the orbitofrontal cortex in humans, but it is important to classify the distinct patterns of sulci and gyrus in this region.

Considering these points, Chiavaras and Petrides ${ }^{6}$ studied it based on magnetic resonance images of human brain, and analyses of monkey brain surface. They proposed to divide the orbitofrontal cortex variation into three patterns according to the orbital sulcus visual appearance. In 2010, Charikova et al. ${ }^{7}$ refined Chiavaras' classification system adding an undescribed pattern, based also on magnetic resonance images.

Regardless of the clinical importance of the orbitofrontal cortex, as far as we know there is not yet an anatomical study comparing and characterize this surface in human brain.

Therefore, we analyze the human brain orbitofrontal cortex in the neuroanatomy laboratory of Universidade Federal de São Paulo.

\section{METHOD}

We analyze eighty four human hemispheres, coming from neuroanatomy laboratory of Federal University of Sao Paulo. All of them were fixed in a $10 \%$ formalin solution. We remove the arachnoid membranes and dissect the orbitofrontal surface of frontal lobe of each one using a surgical microscope (KAPS model SOM 82, Germany). After that, we fill a detailed protocol for each hemisphere (the same person has analyzed all the hemispheres). Then we chose four hemispheres (one of each pattern) and dissect them according to Klinger' technique ${ }^{8}$ aiming to expose the subcortical white matter of the orbitofrontal cortex. The focus was to study the sulci and gyrus of the orbitofrontal cortex, the main configuration of this region and the white matter adjacent to the orbitofrontal cortex. We have done a review of the literature related with orbitofrontal cortex anatomy as well.

\section{RESULTS}

We found, in all hemispheres analyzed, five main sulcus: olfatory sulcus, orbital medial sulcus, orbital lateral sulcus, orbital transverse sulcus and orbital intermediate sulcus. The medial and lateral orbital sulcus can be divided into anterior and posterior portions taking into consideration its connection with the transverse sulcus. These sulcus delimit the orbital gyrus. The anterior orbital gyrus is situated anterior to the transverse sulcus and between the anterior portions of the lateral and medial orbital sulcus. The medial orbital gyrus is situated medial to the medial orbital sulcus and lateral to the olfatory sulcus. The lateral orbital gyrus is situated lateral to the lateral orbital sulcus and join the pars orbitalis of the inferior frontal gyrus. The posterior orbital gyrus is situated posterior to the transverse orbital sulcus (Figure 1).

The olfatory sulcus, the most medial of the orbitofrontal sulcus, accommodate the olfatory tract and the olfatory vein. Its posterior end in all the hemispheres studied is the olfatory trigone and its anterior end can bend medially (28/84), bend laterally (20/84), touch the division between orbitofrontal surface and medial surface of frontal lobe $(27 / 84)$ or go beyond achieving the medial surface of frontal lobe (9/84). The posterior end of olfatory sulcus, after touch the olfatory trigone, can bend laterally in a hook-like shape (20/84) and hence can merge with an orbital sulcus (in the brains that we have studied, among 20 hook-like shape ending of olfatory sulcus, only 8 merge exclusively with the posterior medial orbital sulcus).

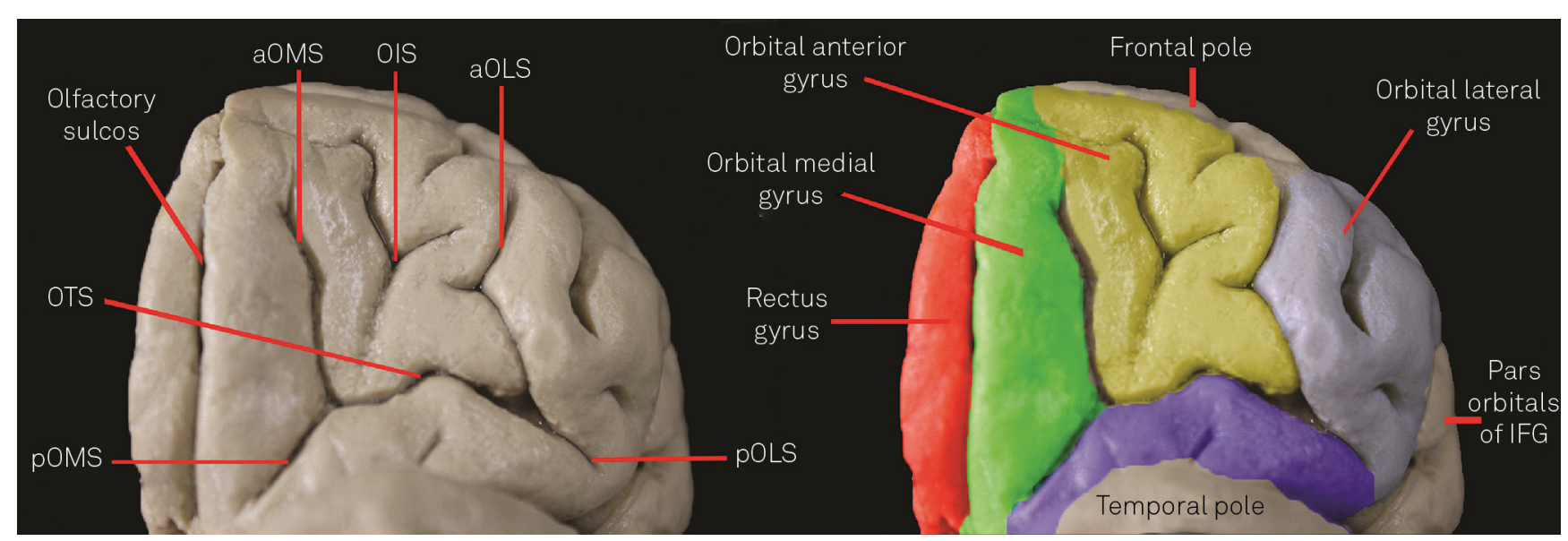

Figure 1. On the left, we expose the orbitofrontal cortex to characterize the sulcal pattern. On the right, we characterize the gyrus using colors. aOLS: Anterior portion of the orbital lateral sulcus; aOMS: Anterior portion of the orbital medial sulcus; IFG: Inferior frontal gyrus; OIS: Orbital intermediate sulcus; OTS: Orbital transverse sulcus; pOLS: Posterior portion of the orbital lateral sulcus; pOMS: Posterior portion of the orbital medial sulcus. 
The intermediate sulcus, a deep longitudinal-oriented sulcus between the anterior portions of the medial and lateral orbital sulcus, were found in all hemispheres and usually takes a form of the greek letter "lambda" (Figure 2).

The posterior orbital sulcus were found in 59/84 hemispheres, and can be connected with the transverse orbital sulcus or can be an intragyral sulcus contained in the posterior orbital gyrus.

The posterior orbital gyrus, in all of the studied hemispheres, is connected with the transverse insular gyrus (Figure 3).

We also divided the orbitofrontal cortex general configuration according to Chiavaras' classification modified by Charikova et al. ${ }^{6,7}$. In this classification, the type I pattern is characterized by a continuous lateral orbital sulcus and a clearly distinct anterior medial and posterior medial orbital sulcus. The type II pattern is the well described "H-pattern", in which the anterior and the posterior portion of the medial and lateral orbital sulcus are connected. In the type III pattern, anterior and posterior portions of the both medial and lateral orbital sulcus are separated. The type IV pattern has a continuous medial orbital sulcus and a separated lateral orbital sulcus in anterior and posterior portions (Figure 4).

We observed the type I pattern in 35/84 hemispheres, type II pattern in $31 / 84$ hemispheres, type III pattern in 15/84hemispheres and the type IV patter in 3/84hemispheres. Taking into consideration the hemisphere side, 41/84 were right-sided hemispheres. Among these right-sided hemispheres, 18/41 were type I pattern; 17/41 were type II pattern; 5/41 were type III pattern and 1/41 were type IV pattern. In the left-sided hemispheres, 17/43 were type I pattern; 14/43 were type II pattern; 10/43 were type III pattern and 2/43 were type IV pattern.

We also expose the subcortical white matter of each pattern of hemisphere to show the short association cortical U fibers (Figures 5 and 6). It provides a better visualization of the real sulcal and gyrus conformation of this region.

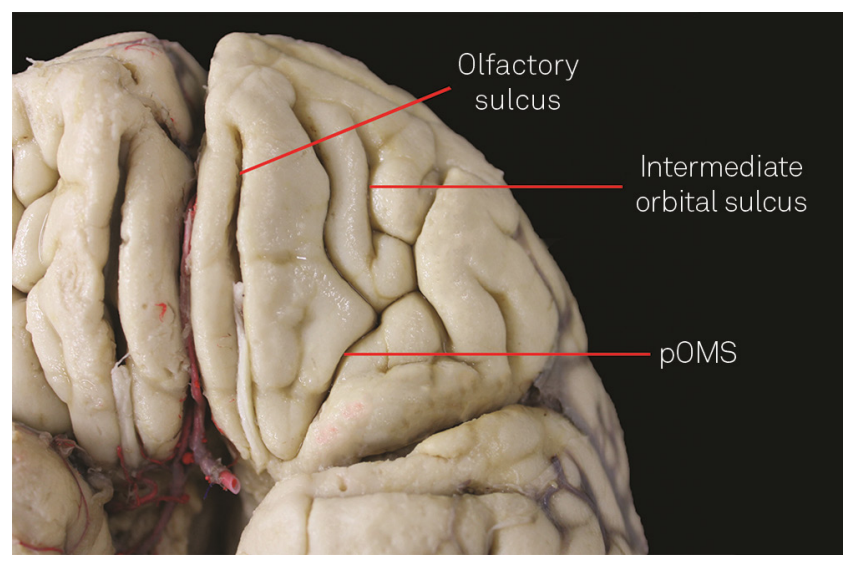

Figure 2. Note that posterior end of the olfactory sulcus, showing a hook-like shape, merge into the posterior portion of the orbital medial sulcus. Also, the intermediate sulcus taking form of the greek letter "lambda".

\section{DISCUSSION}

The main objective of this study is to characterize, by dissecting using the surgical microscope, the orbitofrontal surface according to its sulcal and gyrus anatomy. This sort of anatomical characterization is quite important to a real knowledge of the orbital part of frontal lobe. Instead, none detail anatomical description of orbitofrontal cortex have been found in our research.

There already are many studies that classify the orbitofrontal sulcus and gyrus based on magnetic resonance images and our results were very similar to theirs results ${ }^{6,7,9,10,11}$. For instance, Chiavaras and Petrides (2000) found, among 50 human brains analyzed by Magnetic Resonance Imaging scans, $56 \%$ of type I pattern, $30 \%$ of type II pattern and $14 \%$ of type III pattern. Charikova et al. (2010) found, also using Magnetic Resonance Imaging scans, 56.9\% of type I pattern, $23.6 \%$ of type II pattern, $15.3 \%$ of type III pattern and $4.2 \%$ of type IV pattern in 36 brains of healthy controls.

The fact that our results were similar to previews radiological studies ${ }^{6,7,9,10,11}$ aggregate evidence in the anatomical characterization of the orbitofrontal cortex, as there are two different methods to investigate the same issue with similar results.

In our study, unfortunately we could not find past information, including medical history, genre and age, about the hemispheres analyzed. And, the postmortem human brain fixation method can change the morphology of the hemispheres. This fact can compromised the reliability of precise measurements of sulcus and gyrus characteristics. Therefore, we described our findings in general anatomic language and patterns that are not affect by fixation method.

The presence, in $100 \%$ of the studied hemispheres, of a communication between the posterior orbital gyrus and the transverse insular gyrus, can be an important functional pathway linking the orbitofrontal cortex with the insula lobe

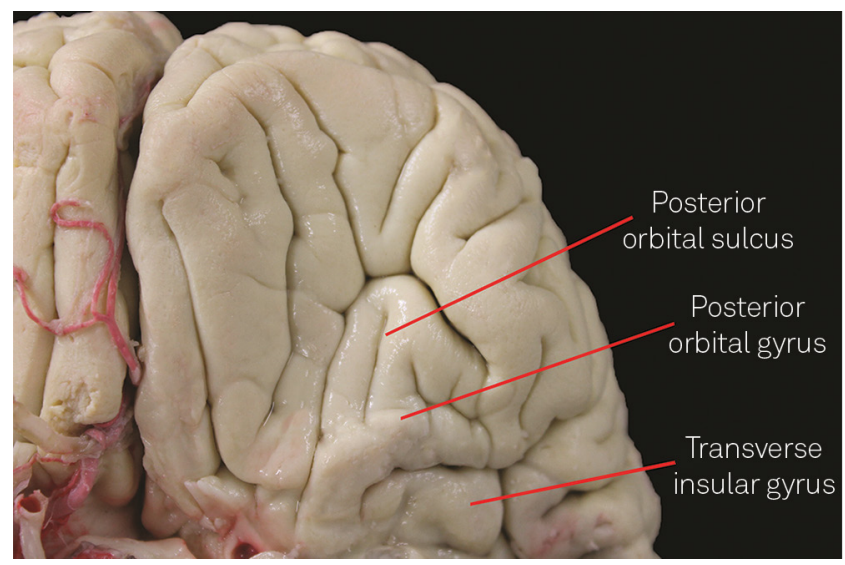

Figure 3. The left temporal pole has been removed to show the connection between the posterior orbital gyrus and transverse insular gyrus. The posterior orbital sulcus, in this specimen, is an intragyral sulcus. 

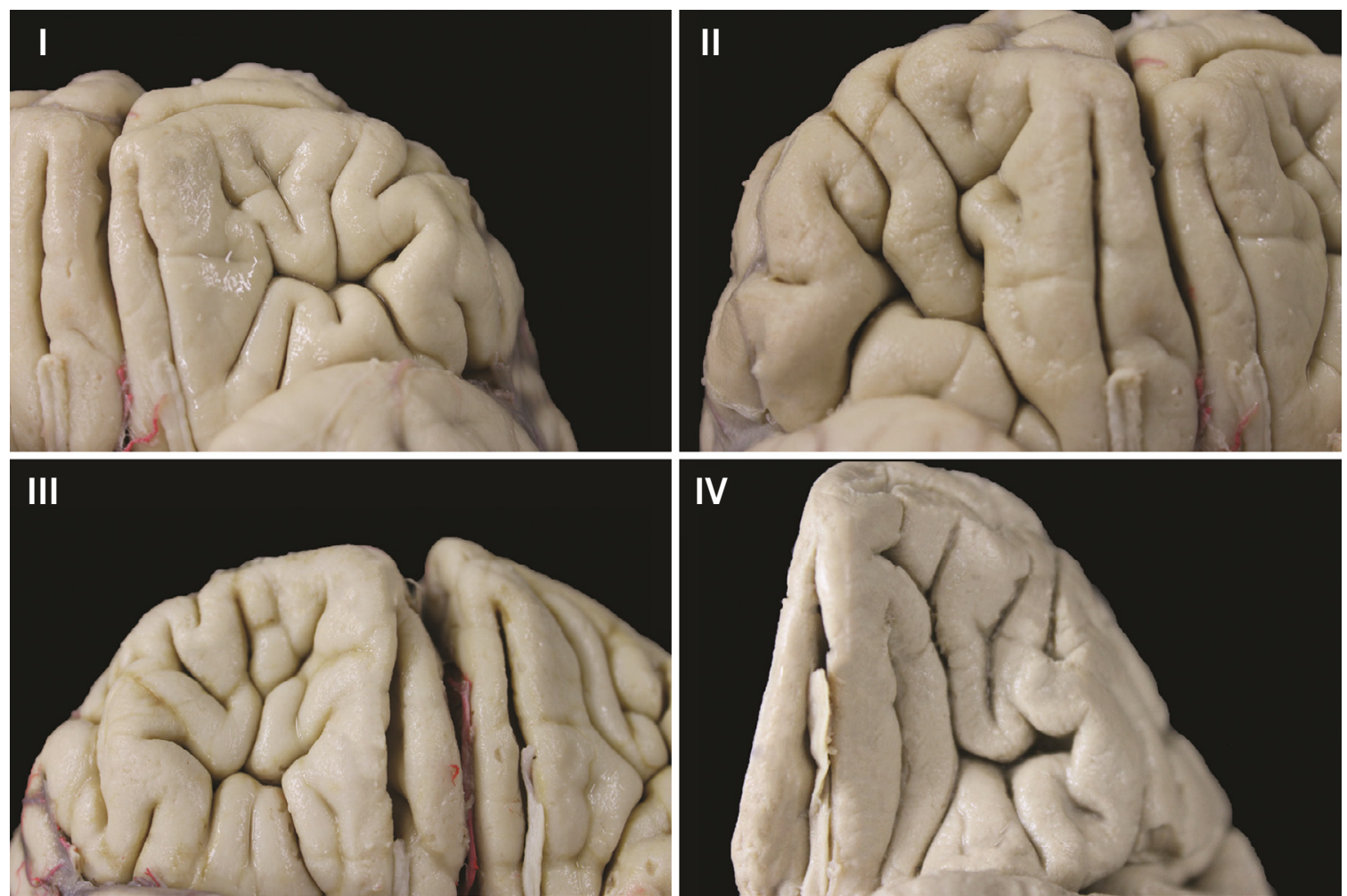

Figure 4. The orbitofrontal cortex patterns. (I) The type I pattern is characterized by a continuous lateral orbital sulcus and a distinct anterior medial and posterior medial orbital sulcus; (II) In the type II pattern the anterior and the posterior portion of the medial and lateral orbital sulcus are connected; (III) The type III pattern shows a separation between anterior and posterior portions of the both medial and lateral orbital sulcus; and (IV) The type IV pattern has a continuous medial orbital sulcus and a separated lateral orbital sulcus in anterior and posterior portions.
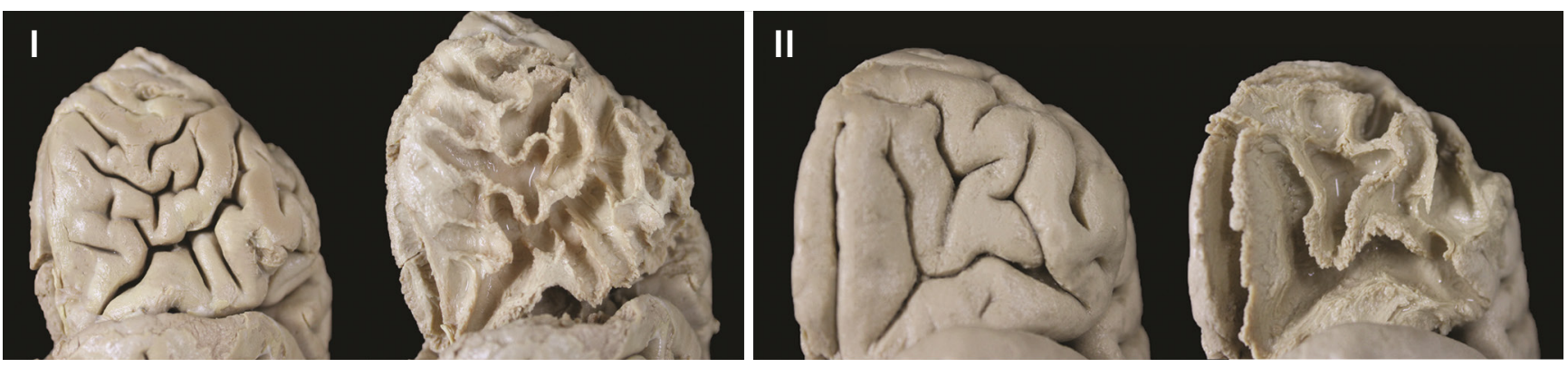

Figure 5. A type I and type II pattern before and after removing the cortex using the Klinge' technique. (I) Note that the orbital lateral sulcus is continuous and the orbital medial sulcus is compound by two separates portions; and (II) A type II pattern showing the both orbital medial and orbital lateral sulcus continuous.
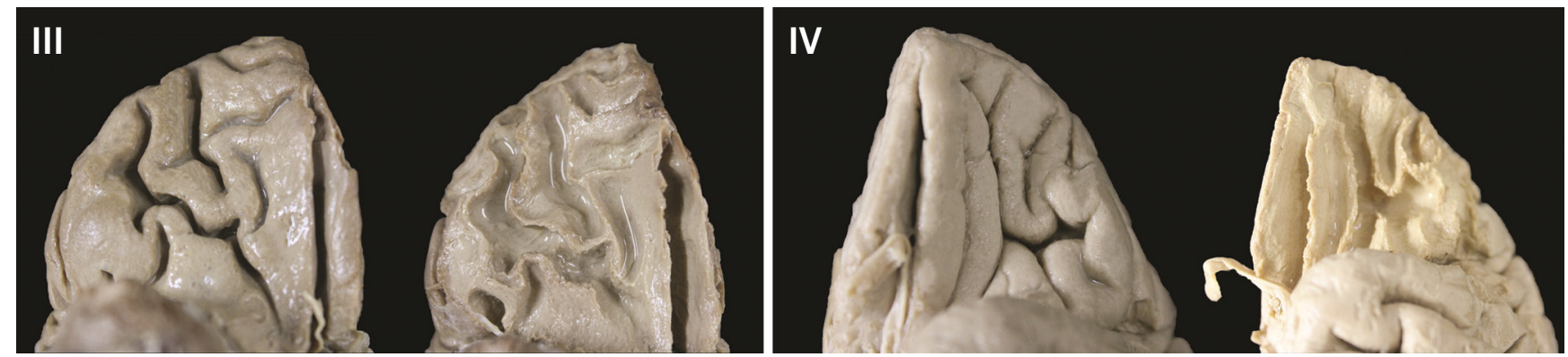

Figure 6. A type III and type IV pattern before and after removing the cortex using the Klinge' technique. (III) Note that the both orbital medial and orbital lateral sulcus are separated in pattern III; and (IV) The rarely found type IV pattern characterized by an continuous orbital medial sulcus and a discontinuous orbital medial sulcus. 
and the basal nuclei region. Observing this gyral communication provide an alternative to insular glioma spreading to orbital part of the frontal lobe.

Since the initial description of orbitofrontal cortex patterns $^{8}$, several studies have showed altered proportion of this basic pattern numbers distribution in psychiatric disorders ${ }^{12}$ and risk of psychiatric disorders ${ }^{7}$.

Further, a bilateral reduction of the medial orbitofrontal gray matter and functional connectivity abnormalities in the orbitofronto-striatal-thalamic-cortical was found in patients with obsessive compulsive disorders ${ }^{13}$. The anterior part of the internal capsule connects the orbitofrontal cortex, the cingulum, and the thalamus ${ }^{14}$. This region was used as target to deep brain stimulation with promising results in the experimental therapy setting ${ }^{15}$.

In conclusion, orbitofrontal cortex is associated with many psychiatric disorders. Better anatomical and functional characterization of the orbitofrontal cortex and its connections will improve our knowledge about this diseases. Functional neurosurgery procedures aiming improve alterations in the orbitofrontal pathways can be an important option to treat these diseases.

\section{References}

1. Nishikuni K, Ribas GC. Study of fetal and postnatal morphological development of the brain sulci. J Neurosurg Pediatr. 2013;11(1):1-11. http://dx.doi.org/10.3171/2012.9.PEDS12122

2. Auladell C, Martinez A, Alcantara S, Supèr H, Soriano E. Migrating neurons in the developing cerebral cortex of the mouse send callosal axons. Neuroscience. 1995;64(4):1091-103. http://dx.doi.org/10.1016/0306-4522(94)00393-J

3. Van Essen DC.A tension-based theory of morphogenesis and compact wiring in the central nervous system. Nature. 1997;385(6614):313-8. http://dx.doi.org/10.1038/385313a0

4. Rhoton Jr AL. The cerebrum. Neurosurgery. 2002;51(4 Suppl 1):S1-51.

5. Jackowski AP, Araújo Filho GM, Almeida AG, Araújo CM, Reis M, Nery F et al. The involvement of the orbitofrontal cortex in psychiatric disorders: an update of neuroimaging findings. Rev Bras Psiquiatr. 2012;34(2):207-12. http://dx.doi.org/10.1590/S1516-44462012000200014

6. Chiavaras MM, Petrides M. Orbitofrontal sulci of the human and macaque monkey brain. J Comp Neurol. 2000;422(1):35-54. http://dx.doi.org/ 10.1002/(SICI)1096-9861(20000619)422:1<35::AIDCNE3>3.0.CO;2-E

7. Chakirova G, Welch KA, Moorhead TW, Stanfield AC, Hall J, Skehel $P$ et al. Orbitofrontal morphology in people at high risk of developing schizophrenia. Eur Psychiatry. 2010;25(6):366-72. http://dx.doi.org/10.1016/j.eurpsy.2010.03.001

8. Klingler J. Erleichterung der makroskopischen praeparation des gehirns durch den gefrierprozess. Schweiz Arch Neurol Psychiatr. 1935;36:247-56.

9. Bartholomeuz CF, Whittle SL, Montague A, Ansell B, McGorry PD, Velakoulis D et al. Sulcogyral patterns and morphological abnormalities of the orbitofrontal cortex in psychosis. Progr Neuropsycopharmacol Biol Psychiatry. 2013;44:168-77. http://dx.doi.org/10.1016/j.pnpbp.2013.02.010

10. Nakamura M, Nestor PG, McCarley RW, Levitt JJ, Hsu L, Kawashima T et al. Altered orbitofrontal sulcogyral pattern in schizophrenia. Brain. 2007;130(3):693-707. http://dx.doi.org/10.1093/brain/awm007

11. Nakamura M, Nestor PG, Levitt JJ, Cohen AS, Kawashima T, ShentonME et al. Orbitofrontal volume deficit in schizophrenia and thought disorder. Brain. 2008;131(1):180-95. http://dx.doi.org/10.1093/brain/awm265

12. Martino J, De Witt Hamer PC, Vergani F, Brogna C, Lucas EM, Vázquez-Barquero A et al. Cortex-sparing fiber dissection: an improved method for the study of white matter anatomy in the human brain. J Anat. 2011;219:531-41. http://dx.doi.org/10.1111/j.1469-7580.2011.01414.x

13. Hou J, Song L, Zhang W, Wu W, Wang J, Zhou D et al. Morphologic and functional connectivity alterations of corticostriatal and default mode network in treatment-naive patients with obsessive-compulsive disorder. PLoS One. 2014;8(12):e83931. http://dx.doi.org/10.1371/journal.pone.0083931

14. Chabardès S, Polosan M, Krack P, Bastin J, Krainik A, David $O$ et al. Deep brain stimulation for obsessivecompulsive disorder: subthalamic nucleus target. World Neurosurg. 2013;80(3-4):S31.e1-8. http://dx.doi.org/10.1016/j.wneu.2012.03.010

15. Blomstedt P, Sjöberg RL, Hansson M, Bodlund O, Hariz MI. Deep brain stimulation in the treatment of obsessivecompulsive disorder. World Neurosurg. 2013;80(6):e245-53. http://dx.doi.org/10.1016/j.wneu.2012.10.006 